\title{
Reflective Relationality in Social Investigation: Theoretical Considerations for Research Practice
}

\author{
Eleonora Venneri ${ }^{1, *}$ \\ ${ }^{1}$ Dept. of Law, Economics and Sociology, "Magna Graecia” University - Viale Europa, \\ Campus Universitario, 88100, Catanzaro, Italy \\ *Corresponding author: Dept. of Law, Economics and Sociology, "Magna Graecia" \\ University - Viale Europa, Campus Universitario, 88100, Catanzaro, Italy. E-mail: \\ venneri@unicz.it
}

Received: January 30, 2020 Accepted: February 9, 2020 Published: March 27, 2020

doi:10.5296/jsr.v11i2.16360ＵRL: https://doi.org/10.5296/jsr.v11i2.16360

\begin{abstract}
This paper offers a theoretical reflection on the epistemological and methodological reasons listing reflexivity among the main practical issues of social investigation. Inspired by the situational logic of the constructivist paradigm, the paper's analysis is limited to the preliminary stages propaedeutic to the operativeness of research, in an attempt to argue the insurmountable condition of contingency and circularity of scientific knowledge and of the procedures themselves which need to be problematised and 'adjusted' to specific situations. Furthermore, starting from a number of assumptions on the implicit constituents of methodological pragmatism, the paper attempts to illustrate its peculiarities with regard to the abductive logic of construction of appropriate indicators for the issues under investigation.
\end{abstract}

Keywords: reflexivity, relationality, indicators, abduction 


\section{Introduction}

Awareness of contexts, relevance of methodologies, appropriateness of research tools: three key issues denoting the reflexivity of virtuous investigation paths, rationally oriented towards the achievement of significant and objectively valid results, which are as faithful as possible to the varied and heterogeneous dimensionality of the realities under investigation and can be reasonably used.

In social sciences, and in the sociological field in particular, reflexivity is the minimum prerequisite for a research intending to be scientific and functional to comprehension, always partial and tolerant of dissimilar or alternative representations of the phenomena under study. Although etymologically connected with a general individual aptitude for scrupulous consideration of actions, it implies clear and careful attention to the 'spaces' and 'situations' in which the events that the researcher deems interesting and intends to operatively investigate take place.

Indeed, this is an epistemological, methodological and technical 'quality' at the same time: the contrivance of strategies presumably more consistent with the study of contextually restricted realities, which are therefore characteristic of peculiar temporal and cultural fields, cannot rely on the impulsive fortuitousness of occasional and imaginative surges or, even worse, on clumsy or incautious improvisation.

On the contrary, reflexivity requires the preventive outline of a logical path, which normally needs to be made explicit and argued and which: $a$ ) is driven by the choice and definition of a cognitive objective (what one intends to study, the type and level of knowledge one can rely on and one intends to increase concerning the subject of the analysis); $b$ ) unfolds in a way that is respectful of distinct and binding procedural rules for each specific choice (how, following which paths and with what means one can reach the objective by approximating its achievement), which are suitable to limit the risk of inappropriate interferences and unjust distortions which might invalidate the reliability of the results and of the entire investigation process.

The backstage of research explored in this paper somehow represents the preferential place for reflexivity and relationality in social investigation. In this case, 'what' and 'how' cannot but be driven by two duly necessary remarks, which are in fact preliminary to any cognitive enterprise.

The first remark leads to observe that the 'objects' of social sciences are not independent and cannot be separated from the situated activity with which and by means of which the researcher has made them observable (Zimmerman \& Pollner, 1970).

The second remark leads to point out that only ingenuously (and wrongly) is it possible to give in to the prejudice of assimilating sociological investigation to the operational 'mise en scène' arranged to carry it out, thereby reducing its sense and content to a merely applicative exercise or, at the most, to a routine exercise of stereotyped techniques.

Additional considerations lead us to support these arguments. For example, the fact that the 
researcher is not a mere outside observer but rather a constitutive and integral part of a pre-interpreted reality, linguistically opaque, dynamic and socially constructed, which is unfit for a mechanical and un-critical reiteration of pre-established or 'ready for use' conceptual schemes or investigation models. Furthermore, the complexity typical of social phenomena forces the researcher to acquire the capacity of unravelling and deconstructing their indeterminacy through ad hoc research practises, each time designed and performed per specific themes or problems, in restricted situations. In addition, the approach to social reality must proceed and be determined by background knowledge and cognitive tools chosen by the researcher so that the 'success' of a methodological procedure in a given situation does not guarantee its effectiveness in any other situation. Finally, the intrinsic instability and socio-cultural peculiarities of investigation contexts refer to a pragmatic meaning of reflexivity demolishing all claims of cognitive exhaustiveness and tending to rethink the methodological paths undertaken when these prove to be unviable or unfit for the problems to be faced.

The aim of offering accessible and useful elements for the reader's reflection on these topics is definitely arduous but not pretentious. In the following pages, without any presumption of completeness, it will be attempted to outline the guiding principles of a scientific path that is desirable and fit for a reflectively sustainable social research, juggling concepts, arguments and controversies typical of a debate which, right from its disciplinary beginnings, pervades sociology and its methodological foundations.

\section{Between Lebenswelt and Scientific Knowledge: Relationality in Social Research}

Rather than a univocal process of validation of ideas previously formulated by others and of pre-defined procedures, social research primarily outlines a cognitive process which 'resists' to premature or preconceived interpretations of reality (Bailyn, 1977; Blaikie \& Stacy, 1982) and is always open to informative stimuli that are not obvious, often unexpected, sometimes even surprising or so stimulating as to give way to an actual revision of one's initial theoretical and conceptual horizons: its 'quality' is demonstrated first of all by its sensitivity to the specific needs of its problem (Toulmin, 1972). Indeed, a conventionally plausible definition of scientific quality of an investigation refers to at least two dimensions which are theoretically contiguous and closely connected and support its cognitive potential and heuristic value: social responsibility and integrity.

Social responsibility generally refers to institutionalised practices of public reporting of behaviours adopted by mutually significant actors (Bovens, 2007; Stahl, Eden, \& Jirotka, 2013); integrity refers to the scrupulous application of principles of honesty, equity, diligence and appropriateness, which are propaedeutic to and regulative of a good methodological and technical 'management', thereby guaranteeing the achievement and spread of qualitatively valuable result. Both call for the need to comply with procedural criteria which engage and bind the researcher to reflect on the socio-cultural specificities of investigation contexts, anthropologically assuming their points of reference and critically arguing their typicalities (Bosch \& Titus, 2009). Indeed, a renewed epistemic awareness gives crucial importance to 
social responsibility, integrity of research and its ethical implications for concrete scientific practice.

With respect to the axiological neutrality and irrationality of such issues, scientistically bound to the respect of preventive criteria of objective truths and incontrovertibly 'certain' knowledge $^{(\text {note } 1)}$, the call for reflexivity is emblematic of the current epistemological scenario which, rather, assumes the relationality of scientific 'objects' as a key element: 'True knowledge continually dialectises the relationship between the observer and the observed ... The objectivity to be researched is the one which integrates the observed into the observation' (Morin, 2005, p. 38, italics in the text).

Whereas reflexivity, as the explicit and conscious meta-analysis of the entire investigation path, represents a methodological antidote to approaches which seem to respect the subjectivities under study but are actually potentially self-referential, relationality gives way to the appropriateness and reliability of knowledge which is in itself contingent, limited by and restricted to cognitive contexts, finalistically oriented to an objectivity '... which does not suppress reality, but tends to account for value options, interests at stake, the importance of context, space and time collocation running through each process of research' (Cipolla, 1997, p. 1938).

Pierre Bourdieu might have intended to refer to this need, defined reflexivity reflex, when he mentioned, among the essential and constitutive dispositions of the profession of social scientist, a cautious 'epistemological supervision':

'Sociologists have to convert reflexivity into a disposition constitutive of their scientific habitus, a reflexivity reflex, capable of acting not ex post, on the opus operatum, but a priori, on the modus operandi (a disposition that will make it impossible, for example, to analyse the apparent differences in statistical data from different countries without looking for the differences hidden between the categories of analysis or the conditions of data gathering linked to the different national traditions which may be responsible for these differences or their absence).' (Bourdieu, 2004, p. 89, italics in the text).

In this perspective, which basically diverts attention from 'abstract' knowledge focusing on practices and contexts in which it acquires significance, the orthodox and linear systematicity of theoretical/operational mainstreaming, which in some ways can be assimilated to the ritualistic repetition of what is already known and, as such, strongly restricts the actual scientific practice, gives way to a dynamic, circular (cyclical) and extremely articulated vision of the investigation process. Speaking of the so-called 'fallacy of misplaced concreteness', Whitehead points out:

'The disadvantage of exclusive attention to a group of abstractions, however well-founded, is that, by the nature of the case, you have abstracted from the remainder of things. In so far as the excluded things are important in your experience, your modes of thought are not fitted to deal with them. You cannot think without abstractions; accordingly, it is of utmost importance to be vigilant in critically revising your modes of abstraction. ... A civilisation which cannot burst through its current abstractions is doomed to sterility after a very limited period of 
progress' (Whitehead, 1926, p. 73).

In other words, there is no 'general theory' of research practice: against the uselessness of projects that are blindly faithful to previously outlined configurations of reality, the awareness of the referentiality of permanently partial and temporary sociological knowledge is unavoidably constitutive of its 'methodological pragmatism'. As stated by Schatzman and Strauss (1973, p. 7), 'the researcher sees any method of inquiry as a system of strategies and operations designed - at any time - for getting answers to certain questions about events which interest him', choosing and adjusting each time the methodologies and tools that are most suitable for the peculiarities of the subjects under analysis. Similarly, 'the results of all social research are limited in time and space. Social and cultural reality is already pre-interpreted by the participants as a cultural symbolic meaning system and these meaning can be changed over time. Therefore, the process of understanding this socially constructed reality is 'dialogic'; it allows individuals to communicate their experiences within a shared framework of cultural meanings. The researcher is a 'reflective partner' whose relationship is that of subject to co-participant' (Blaikie, 2010, p. 52).

There is an implicit reference to an implied principle of rational indetermination, closely connected with cultural factors which determine the start and development of a research process and influence its methodological and technical options (Dewey, 1938; Kriz, 1992): instead of 'assembling' results, the researcher actively participates in building relations that are ethically oriented towards the enhancement of the identity of the subjects under study.

The definition assimilating the concept of 'responsible research' to a transparent and dialectic argumentation process, through which the subjects involved, in various ways, in the generation and use of scientific advances become mutually reactive, pleading its admissibility and ethical sustainability (Von Schomberg, 2011; Stahl et al., 2013) has now been widely confirmed. In scientific enterprise in particular, 'being socially responsible means not only fulfilling legal expectations, but also going beyond compliance and investing 'more' into human capital, the environment and the relations with stakeholders' (Commission of the European Communities, 2001, p. 5, our italics).

However, especially in the sociological field, this recommendation is not only corroborated but also burdened by an additional 'objectivity obligation': since this transaction cannot be trivially assimilated to an exchange but rather to an active process of mutual 'building' which emphasises the situational bond by exorcising all dualistic representations of the research process, the compromise between the scientific value of the information that can be gathered with the least possible level of distortion and the potential risks for 'co-protagonists' represents a fundamental interpretational turning point.

In fact, if social scientists are inevitably 'part' of the problem they are trying to solve, a reliable faithfulness of research results implies, first of all, responsibly giving up attitudes that are autarkic and reluctant to the review, modification and potential abandonment from 'their' modes of representation of the reality under study, thereby drawing from symbolic universes that can be alternative to 'their' interpretational categories, in order to co-build and share languages and significations. Indeed, 
'The richness of the interpretations proposed and of the 'ideas' resulting from a research is proportional to the extent to which a researcher is willing to question those he started with (and himself as a person) in order to establish an equal dialogue (within situational boundaries which are not equal) with the subjects under study. (...) Especially in an ever more multicultural world, in which the vital worlds of people are less shared, decipherable and predictable, this capacity of relativising one's pre-judices and humbly listen is the only guarantee for the cognitive enrichment of research' (Palumbo, 2012, pp. 7-8).

This leads to a call for relationality, for intersubjective relativity of the investigation process $^{(\text {note } 2)}$ and, therefore, for the reassessment of Lebenswelt, intended as the foundation and source of the formation of meaning of all theoretical constructions (Waldenfels, 1985), with respect to 'objectivistic' drifts of scientific knowledge.

If, as already mentioned in the introduction to this paper, it is only by virtue of naive inexperience that one can give in to the prejudice (which is actually fairly common, hopefully only among non-experts) of assimilating and reducing social research to the tools used to achieve it, it is worth mentioning that the definition of research techniques, as sophisticated or 'trendy' as it may be, is not sufficient, in itself, to qualify the scientific job tout court.

In the same way, believing that experience in a scientific context is independent of cultural bonds and that scientists' observations have nothing to do with everyday experience and biological, psychological and social conditioning is a 'dangerous myth' (Kriz, 1992).

On the contrary, the direction of research depends on the uniqueness of the context in which it is inserted and its development and meaning are guided precisely by direct experience of the situation of investigation (Dewey, 1938, p. 68).

\section{A look at Indicators: Reasonableness and Reflexivity in Construction Processes}

As it was attempted to demonstrate, one of the conditions for relationality and reflexivity of an investigation lies in the analyst's disposition to develop a wise distrust of cognitive apriorisms, incautious suppositions and misleading inferences, as well as to carry out a constant epistemological exercise of attention to the elements, often latent, of the realities that are being compared. Indeed, this means adopting a non-linear and multidimensional investigational criterion, 'centrally concerned with seeking to understand relationship between the knower and the known as well as seeking to understand what is the form and nature of the reality' (Tidwell, Heston, \& Fitzgerald, 2009, p. XIII), with the aim of intercepting implicit suggestions and 'tacit' knowledge, which are not infrequently hidden 'in the recesses of the ordinary' (Perla, 2010, p. 89), thereby avoiding any potential formalisation.

In particular, this cognitive style tackles problems without an ineffective reductionist approach; it regenerates the factors of legitimation and consent supporting and motivating the presence of the researcher in the investigation field through dialogue forms of 'deutero-learning' (Bateson, 1972); it modifies the practises of knowledge acquisition, 
processing and transmission; it is mainly oriented towards a dynamic and mutual arrangement of different identities, with wide margins of 'creativity' (Poincaré, 1920) and negotiation in the choice of descriptive/interpretative languages and codes for the phenomena under study. In actual fact, a reasoned and never random selection of appropriate, relevant indicators for research contexts also implies these issues.

It is common knowledge that language implies deep symbolic meanings, which often prevail over the contents conveyed (Garfinkel, 1967). The correspondence between the structure of language and the meanings assigned to perceived objects can be considered as 'imperfect' (Cicourel, 1964): each semiotic act is never fully definite and repeatable and is bound to be influenced by the 'history' and culture of humans in their quality of sign producers; each sign occurrence is therefore new and interpretative; meanings themselves have a 'contingent' and 'local' nature, with high levels of flexibility and variability ${ }^{\text {(note } 3)}$.

In the same way, language is an integral part of conceptualisation, it integrates uses, social conventions, locutions of common sense and does not represent a technical tool or a label for mere transmission of information. Rather, it can be assimilated to a complex, articulated weave conveying cultural meanings which are 'proper' to peculiar social realities and do not admit simplistic operations of 'translational equivalence'.

In this multiple weave the indicator serves as a 'mediator' between concepts referred to different systems of signification; thus, it requires 'contextual instructions' aimed at regulating its decoding, use and potential outcomes in different fields (Eco, 1981). This leads to a series of remarks supporting the importance of a reflective approach to the construction of indicators, whose relevance is defined 'first of all by the community of speakers, whether a specific scientific community or a general territorial-based community' (Palumbo, 2003, p. 110): the possible uses of an indicator are not fixed but rather characteristic of particular situations; it is very difficult to call for rules of theoretical/operational correspondence or equivalence between concepts and indicators, without the inevitable production of 'mimetic effects' on the dynamics under observation and of interpretations that are so general as to become generic or useless.

In other words, if indicators represent levels of intermediate conceptual abstraction: based on which criteria is it appropriate to choose indicators? Do logically exhaustive indicators of a phenomenon exist? Can the conjunction between concepts and indicators be referred to a criterion of truth or, rather, to a requirement of acceptation?

Besides evoking problems related to the syntactic and semantic approaches to the relationship of indication, which have been already widely discussed by the methodological tradition, a plausible answer to these questions may be referred to the distinction between two distinct procedures oriented towards the identification, propaedeutic to the construction of the relevant indicators, of the problematic areas of a phenomenon: the first one, of a logic nature, leads back to the possibility of identifying its dimensions and respective indicators in an analytical and intensive sense; the second one, of an epistemological nature, implies the possibility of achieving this identification in an empirical and extensive sense. 
In the first case, the dimensions and indicators of a complex concept are 'given': due to the accumulation of previous investigations and previously formulated theories, there is a satisfactory homogeneity of meaning and a wide consent among the scientific community to the dimensions and indicators of the phenomenon which the concept tends to approximate; in Hempel's words (1952), the sense of the phenomenon is 'already known' and its analysis is carried out while providing an isomorphic and synonymous expression of $\mathrm{it}^{\text {(note } 4)}$. In the second case, instead, the identification of dimensions and indicators does not concern linguistic expressions and their meanings; rather, it aims at establishing which empirical characteristics must necessarily emerge for a coherent representation of the concepts analysed: this leads from the stipulative and conventional level of a 'nominal' definition to its 'factual characterisation' (Pasquinelli, 1970).

At an intensive level of conceptualisation, the conditions of classification are roughly met, thereby achieving the construction of a model which, synthetically, represents a series of indicators logically organised according to a detailed hypothesis plan. At an extensive level, the representativeness of a self-evident indicator, essential and coherent within a theoretical plan which is in itself self-sufficient (Carley, 1981), has to deal with its 'revelation ability' instead. The latter:

'Prefers the variability of a given phenomenon and seizes its 'minor' yet enlightening components. It does not concern the whole population, it stops before quantity, offers a modest empirical contribution, yet full of meanings due to the richness of its conceptual implications, thereby revealing its deepest consequences, the ones which are actually growing and with the greatest explanatory force' (Cipolla,1995, p. 370).

In the context of an investigation oriented to the search of 'interpretational keys' of society that, turning towards the exploration of specific meanings assigned by communities to complex, dynamic, diverse needs, which are not liable to categorisation, requires suitable processes for de-constructing well-established representations of reality, the quotation reported above is not coincidental. It turns out to be particularly useful for the purposes of a general remark: if, with respect to 'objectivistic' designations of social reality, it were possible to pre-suppose the neutrality and exhaustiveness of the indicator, its heuristic value would be certainly (and seriously) damaged.

Similar doubts remain with regard to the problem of the relationship between indicators and the information they 'convey': among the various attempts to develop 'types' of indicators, some are so detailed in their descriptions that, on the one hand, they manage to seize each conceivable category and, on the other, they appear to be honestly difficult to manage or impracticable and 'scientifically unsustainable', given the substantial difficulty in assuming 'an explicit or explicitable system of preferences, stable in time and space, complete and organic, so as to allow to express the weight of each indicator in numerical terms' (Palumbo, 2003, p. 125).

In this perspective, which, by virtue of inclusion and dialogue among the 'actors' of the research process, exorcises the 'threat to the partiality of choices' (House \& Howe, 1999) attributable to knowledge paths leading back to axiomatic conditions and predefined 
procedural criteria, the 'practicability' and logical and empirical 'congruence' of an indicator are measured within an 'integrated' methodological strategy that denies the exclusive legitimation of operational and 'autocratic' approaches (Galtung, 1967), and 'transcends the partial and separate use of cognitive techniques and strategies and accepts temporary or limited observations, i.e. gathered on certain fronts of reality with a given technique, which must be constantly added, compared, made mutually functional in order to approximate the social reality of reference as powerfully as possible' (Cipolla, 1995, p. 365).

An allusion is made to the adoption of a construction criterion inspired by abductive logic

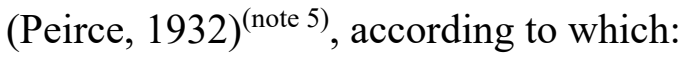

Objectivity cannot be a quality or an attribute of the indicator in itself, but needs to be related to the character of the symbols through which phenomena are communicated.

- The choice of an indicator must take into special consideration the underlying (and different) levels of conceptualisation of social phenomena (material and immaterial) which indicators aspire to represent.

- The value of an indicator cannot be determined beyond the conceptual structure from which it emerges; only such structure may establish its acceptance and relevance.

- An indicator has a conditional and hypothetical value which is temporarily accepted and used during the investigation.

- An indicator in itself is determinate in comparison with its object, 'uses meanings' and designates, in turn, a 'critical' and 'significant' concept within a given problem situation.

- It is the 'problem' caused by the situation to control its function; if isolated from the context situation, its logical effectiveness remains indeterminate (Venneri, 2007, 2010).

Thus, indicators' selection processes are not governed by a cognitive requirement for sufficient adequacy ${ }^{6}$. Rather, they are strongly dependent on the 'moment' in which the criteria themselves are developed; the denotative relation between indicators and the 'sensitive features' of selected objects can 'only refer to objects denoted and experimented in the present since the selection of the object depends on current conditions and cannot be made according to conditions existing yesterday or tomorrow, for instance' (Pardi, 2002, p. 157).

A strong opposition ensues between the unconditional value of arbitrarily constructed and somehow 'imposed' indicators and the social value of a reasonable choice made transparent to critics by an argument. If denominating appears as a strange connection of a word with an object (Wittgenstein, 1967), it is easier to understand how the use of an indicator does not depend on general or universal rules, but on the particular rules of denomination in use among a particular form of life.

In the resulting communicational characterisation, the 'technocratic' vision of the research process, in which the pre-definition of the categories of the thinkable ends up pre-defining the categories of thought (Bourdieu, 1984), resists to the temptation of a final synthesis of skills and subjects them to the trial of inclusion, deliberation and dialogue among different 
symbolic competences.

\section{Conclusion}

The logic just outlined, circumscribes an specifically approach to practice of social research which tends to develop as an indefinitely open sequence of 'construction of meanings', moving from the interpretation of perspectives, aspirations, topics and actions of all people involved in the research programs, in relation to the organisational, social and cultural contexts in which the research is implemented. For this reason, the relational logic of research interrupts the 'contextual continuity' of repetitive situations, of stable expectations and of lasting relations typical of the methodological mainstream and, with it, the defence of routine guiding principles for action. Once again, this means claiming that, compared to research programs traditionally inspired by 'linear causation' interpretational models, social research supports processes that are mainly involved in the activation and the structuration of contexts which, due to 'reciprocity', facilitate reflexivity and effective of sustainable social relations.

\section{Acknowledgement}

The research is financed by Ministerial fund for the financing of basic research activities (FFABR)

\section{References}

Bailyn, L. (1977). Research as a Cognitive Process: Implications for Data Analysis. Quality and Quantity, 11(2), 97-117. https://doi.org/10.1007/BF00151906

Bateson, G. (1972). Steps to an ecology of mind. New York, NY: Ballantine Books.

Blaikie, N. (2010). Designing Social Research: The Logic of Anticipation. Malden, MA: Polity Press.

Blaikie, N., \& Stacy, S. J. G. (1982). The dialogical generation of typologies in the study of the care of the aged. In: X World Congress of Sociology, August, Mexico City.

Bosch, X., \& Titus, S. L. (2009). Cultural challenges and international research integrity. The Lancet, 373(9664), 610-612. https://doi.org/10.1016/S0140-6736(09)60379-2

Bourdieu, P. (1984). Distinction: A Social Critique of the Judgement of Taste. Cambridge, MA: Har-vard University Press.

Bourdieu, P. (2004). Science of Science and Reflexivity. Chicago, IL: The University of Chicago Press.

Bovens, M. (2007). Public Accountability. In: E. Ferlie, L. E. Lynn Jr, \& C. Pollitt (Eds.), The Oxford Handbook of Public Management. Oxford: Oxford University Press. 
https://doi.org/10.1093/oxfordhb/9780199226443.003.0009

Carley, M. (1981). Social Measurement and Social Indicators: Issues of Policy and Theory. Londra: George Allen \& Unwin.

Cicourel, A. V. (1964). Method and Measurement in Sociology. New York, NY: The Free Press.

Cipolla, C. (1995). Teoria della metodologia sociologica. Milano: FrancoAngeli.

Cipolla, C. (1997). Epistemologia della tolleranza. Milano: FrancoAngeli.

Commission of the European Communities. (2001). Green Paper. Promoting a European framework for Corporate Social Responsibility. Brussels, 18 July. Brussels: COM.

Dewey, J. (1938). Logic, the Theory of Inquiry. New York, NY: Henry Holt and Company.

Eco, U. (1981). Segno. In Enciclopedia Einaudi. Vol XII. Torino: Giulio Einaudi.

Galtung, J. (1967). Theory and Methods of Social Research. New York, NY: Columbia University Press.

Garfinkel, H. (1967). Studies in Ethnomethodology. Englewood Cliffs, NJ: Prentice-Hall.

Hempel, C. G. (1952). Fundamental of Concept Formation in Empirical Science. Chicago, IL: University of Chicago Press.

House, E. R., \& Howe, K. R. (1999). Values in Evaluation and Social Research. Thousand Oaks, CA: Sage.

Kriz, J. (1992). Senso comune e tecniche di ricerca. In: A. Marradi \& G. Gasperoni (Eds.), Costruire il dato 2. Vizi e virtù di alcune tecniche di raccolta delle informazioni, 1-14. Milano: FrancoAngeli.

Morin, E. (2005). Lo spirito del tempo. Roma: Meltemi.

Palumbo, M. (2003). Gli indicatori valutativi. Rassegna italiana di valutazione, VII(27), 107-129.

Palumbo, M. (2012). Prefazione. In: F. Ciucci (Ed.), L'intervista nella valutazione e nella ricerca sociale. Parole di chi non ha voce, 7-9. Milano: FrancoAngeli.

Pardi, F. (2002). Verità e attivazione in sociologia. In: C. Cipolla (Ed.), Il nodo di Gordio: verità e sociologia, 150-164. Milano: FrancoAngeli.

Pasquinelli, A. (1970). Nuovi principi di epistemologia. Bologna: Clueb.

Peirce, C. S. (1932). Collected Papers of Charles Sanders Peirce. Cambridge, MA: Harvard University Press.

Perla, L. (2010). Didattica dell'implicito. Brescia: La Scuola.

Poincaré, H. (1920). Science et Méthode. Paris: Ernest Flammarion Éditeur. 
Schatzman, L., \& Strauss, A. L. (1973). Field research. Strategies for a Natural Sociology. Englewood Cliffs, NJ: Prentice-Hall.

Stahl, B. C., Eden, G., \& Jirotka, M. (2013). Responsible Research and Innovation in Information and Communication Technology: Identifying and Engaging with the Ethical Implications of ICTs. In: R. Owen, J. Bessant, \& M. Heintz (Eds.), Responsible Innovation. Chichester: Wiley. https://doi.org/10.1002/9781118551424.ch11

Tidwell, D., Heston, M., \& Fitzgerald, L. (Eds.). (2009). Research Methods for the Self-Study of Practice. Dordrecht: Springer.

Toulmin, S. (1972). Human Understanding. Vol. 1: The Collective Use and Evolution of Concepts. Princeton, NJ: Princeton University Press.

Venneri, E. (2007). Indicatori sociali e valutazione: scenari, acquisizioni, prospettive. Salute e Società, 2, 42-64.

Venneri, E. (2010). L'indicatore riflessivo: logica argomentativa ed ermeneutica nei processi di costruzione. In: C. Bezzi, L. Cannavò, \& M. Palumbo (Eds.), Costruire e usare indicatori nella ricerca sociale e nella valutazione, 80-93. Milano: FrancoAngeli.

Von Schomberg, R. (Ed.). (2011). Towards Responsible Research and Innovation in the Information and Communication Technologies and Security Technologies Fields. Luxembourg: Publications Office of the European Union. https://doi.org/10.2139/ssrn.2436399

Waldenfels, B. (1985). In den Netzen der Lebenswelt. Frankfurt am Main: Suhrkamp.

Whitehead, A. N. (1926). Science and the Modern World: Lowell lectures, 1295. Cambridge, UK: Cambridge University Press.

Wittgenstein, L. (1967). Ricerche Filosofiche. Torino: Einaudi.

Zimmerman, D. H., \& Pollner, M. (1970). The Everyday World as a Phenomenon. In: J. D. Douglas (Ed.), Understanding Everyday Life: Towards a Reconstruction of Sociological Knowledge, 80-103. London: Routledge \& Kegan Paul. https://doi.org/10.4324/9781351327329-4

\section{Notes}

Note 1. Reference is made to the epistemological characteristics of the reductionist ideal supported by classic determinism and its gradual abandonment predicted and widely discussed by the formulation of Werner Heisenberg's 'principle of indetermination' (1962: 58): 'We have to remember that what we observe is not nature in itself but nature exposed to our method of questioning'.

Note 2. The relativity of the research process mainly derives from the radical incompleteness of the interpretation of the 'world of the other' (life world) which consists of concepts, 


\section{Macrothink

judgments, principles, common sense representations, languages and meanings that can be drawn by the observer only for very modest parts and never definitively.

Note 3. As Geertz (1973: 5) points out, 'man is an animal suspended in a network of meanings that he has woven himself. Culture is one of these networks and its analysis is not, therefore, an experimental science in search of laws, but an interpretative science in search of meanings'.

Note 4. Suffice it to think about the implications of the so-called 'restricted thesis of empiricism', the forerunner of the possibility to translate each scientific proposition, as abstract as it may be, into an equivalent proposition expressed in mere observational terms by means of adequate definitions of its constitutive technical terms.

Note 5. The abductive suggestion arouses useful reflection in order to assimilate the indicators' construction process to a path of pragmatic transmission of 'critical' social learning.

Note 6. This refers to the metaphysical concept of truth as a 'reflection' of the objective reality: in particular, the indicator would constitute a normative principle of practical activity with reference to an ideal 'order' which social reality would imperatively have to comply with.

\section{Copyright Disclaimer}

Copyright for this article is retained by the author(s), with first publication rights granted to the journal.

This is an open-access article distributed under the terms and conditions of the Creative Commons Attribution license (http://creativecommons.org/licenses/by/3.0/). 